\title{
Video-assisted thoracoscopic surgery lobectomy - early experience
}

\author{
Jozef Belák, Marián Kudláč, Robert Šimon \\ $2^{\text {nd }}$ Department of Surgery, Pavol Jozef Šafárik University, Medical Faculty, University Hospital of L. Pasteur, Košice, Slovak Republic
}

\begin{abstract}
Introduction: Video-assisted thoracoscopic surgery (VATS) lobectomy is the anatomical resection of a whole lobe of the lung followed by removal of the lymph nodes from the mediastinum using a thoracoscope and an access incision (small thoracotomy $\leq 5 \mathrm{~cm}$ ) without using the rib spreader.

Aim: To present the early experience with VATS lobectomy.

Material and methods: Five patients were treated surgically using the VATS technique of anatomical lung resection at the $2^{\text {nd }}$ Department of Surgery, Pavol Jozef Šafárik University, University Hospital of L. Pasteur, Košice, (Slovak Republic) within 12 months from 10.2008 to 10.2009. Lobectomy was performed in 4 patients and pneumonectomy in 1 patient.

Results: The mean operating time was $120 \mathrm{~min}$ (range 80-170 min). Following lobectomy a drain was inserted into the pleural cavity in 4 cases, whereas there was no drainage after 1 pneumonectomy. Drains were removed 2-5 days after the surgery. Four patients suffered from lung carcinoma (1 squamous cell carcinoma, 3 adenocarcinomas); 1 patient had chondroid hamartoma. Postoperative condition was good in all patients. There were no early complications and patients were released home on the $6^{\text {th }}$ postoperative day on average.

Conclusions: The advantages of VATS lobectomy have been widely discussed. There is a consensus that in elderly patients with non-small cell lung cancer VATS lobectomy accompanied by mediastinal lymphadenectomy reduces the incidence of complications after the surgery and patients recover faster.
\end{abstract}

Key words: VATS lobectomy, non-small cell lung cancer

\section{Introduction}

The first report on the minimally invasive approach in thoracic surgery treatment of pneumothorax was published in 1990 [1]. In 1993 Kuby and Rice reported their experience with video-assisted thoracoscopic surgery (VATS) lobectomy in a patient suffering from non-small cell lung cancer clinical stage one [2]. VATS lobectomy is defined as anatomical lung resection followed by mediastinal lymphadenectomy using a thoracoscope and an access incision (small thoracotomy $\leq 5 \mathrm{~cm}$ ) without the application of the rib spreader (retractor) into the intercostal area.

\section{Material and methods}

Five patients were treated surgically using the VATS technique of anatomical lung resection at the $2^{\text {nd }}$ Department of Surgery, Pavol Jozef Šafárik University, University Hospital of L. Pasteur, Košice (Slovak Republic), within 12 months from 10.2008 to 10.2009. Lobectomy was performed in 4 patients and pneumonectomy in 1 patient (Table I). In 4 cases the reason for the operation was a non-small cell lung cancer, in 1 a chondroid hamartoma. The mean age of patients was 58 years (range 43-70 years); the group consisted of 4 males and 1 female patient. All the 
Table I. Patient characteristics

\begin{tabular}{|c|c|c|c|c|c|c|}
\hline Patient & VATS resection & $\begin{array}{l}\text { Histological } \\
\text { diagnosis }\end{array}$ & $\begin{array}{l}\text { TNM } \\
\text { staging }\end{array}$ & Transfusion & $\begin{array}{c}\text { Drain removed } \\
\text { (postoperative day) }\end{array}$ & $\begin{array}{l}\text { Operative } \\
\text { time [min] }\end{array}$ \\
\hline Male $68 \mathrm{y}$ & Right lower lobe lobectomy & $\begin{array}{c}\text { Squamous } \\
\text { cell carcinoma }\end{array}$ & T2NOMO & 0 & 5 & 95 \\
\hline Male 56 y. & Pneumonectomy on the left & Adenocarcinoma & T3NOMO & 0 & No drain & 105 \\
\hline Male 70 y. & Right upper lobe lobectomy & Adenocarcinoma & T1NOMO & 1 unit PRC & 5 & 150 \\
\hline Female $53 \mathrm{y}$. & Right upper lobe lobectomy & Adenocarcinoma & T2NOMO & 0 & 3 & 80 \\
\hline Male 43 y. & Right lower lobe lobectomy & $\begin{array}{l}\text { Chondroid } \\
\text { hamartoma }\end{array}$ & & 0 & 3 & 170 \\
\hline
\end{tabular}

VATS - video-assisted thoracoscopic surgery, PRC - packed red cells, TNM - tumor, node, metastasis

patients underwent computed tomography (CT) scan and bronchoscopy prior to surgery. The patients with a focal process in CT scans corresponding to T1-2 size and located at the periphery were scheduled for VATS (Figures 1, 2).

General anaesthesia with tracheal intubation and separate ventilation were used. There was no epidural anaesthesia used for postoperative pain control. The patient was positioned on the side. $5 \mathrm{~cm}$ long incision thoracotomy was performed at the level of the $4^{\text {th }}$ or $5^{\text {th }}$ intercostal space in the anterior axillary line. The rib spreader was not inserted into the intercostal area, but only between the muscles. The intercostal area was chosen according to the tumour location, depending on whether it was in the upper or lower lobe. Two ports were inserted, one at the anterior axillary line, and one in the posterior axillary line, the choice of intercostal space depending on the tumour location and condition in the pleural cavity. Veins were handled with an endostapler or linear TA stapler (Figures 3, 4), bronchus with a linear TA stapler (Figures 5, 6). For intrathoracic preparations traditional instruments were combined with endoscopic tools using classical ligatures. To separate lobes endostaplers were applied. After the removal of pulmonary tissue the resection of mediastinal lymph nodes was performed. In VATS lobectomy cases one drain was inserted into the pleural cavity, while following pneumonectomy drains were not used.

After the surgery, patients were transferred to the ICU. Patients were mobilized the following day. Packed red cell transfusion was required in one patient during the surgery. Drains were removed on the third or fifth postoperative day. The mean operating time was 120 min (range 80-170 min). In

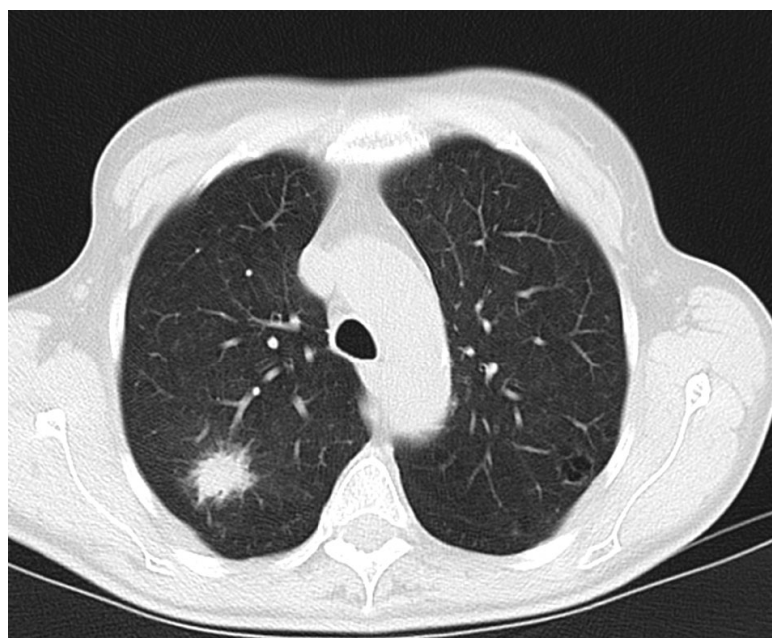

Figure 1. Chest CT scan of a 53-year-old female patient

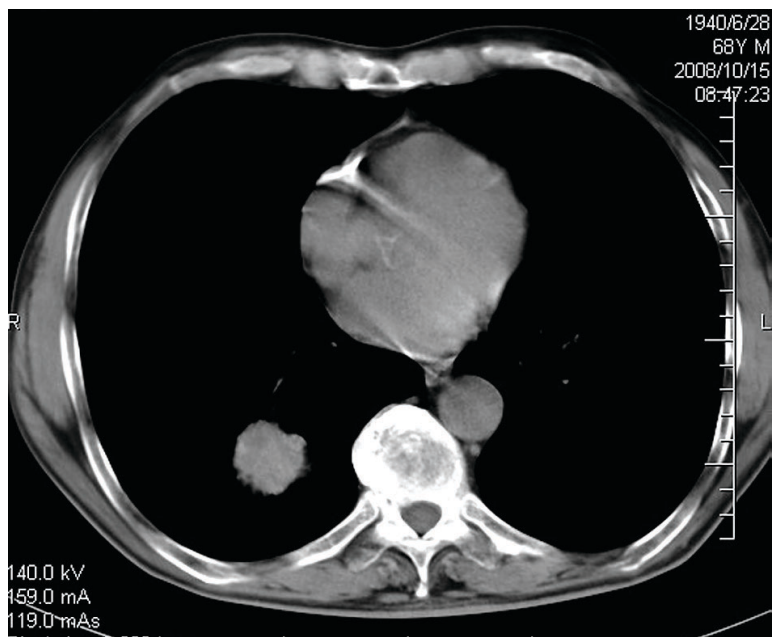

Figure 2. Chest CT scan of a 68-year-old male patient 


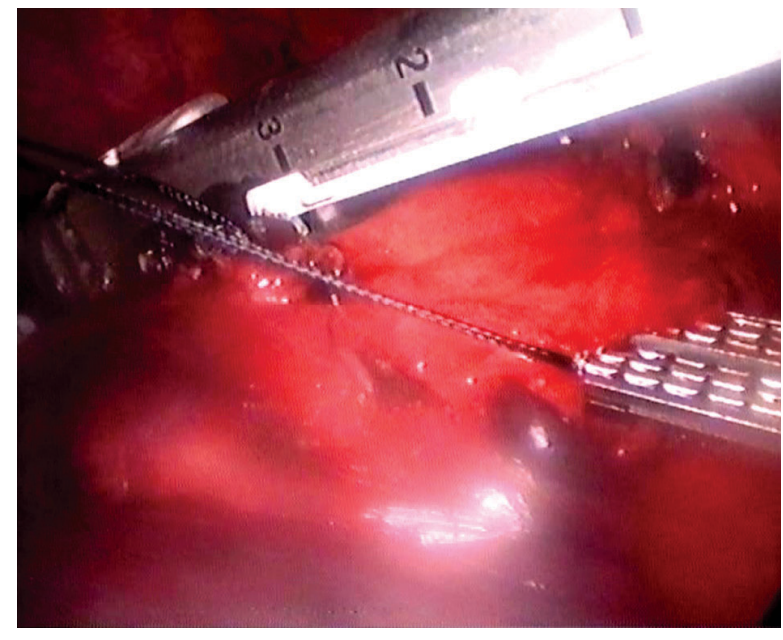

Figure 3. Dissection of the pulmonary artery with Endo GIA stapler

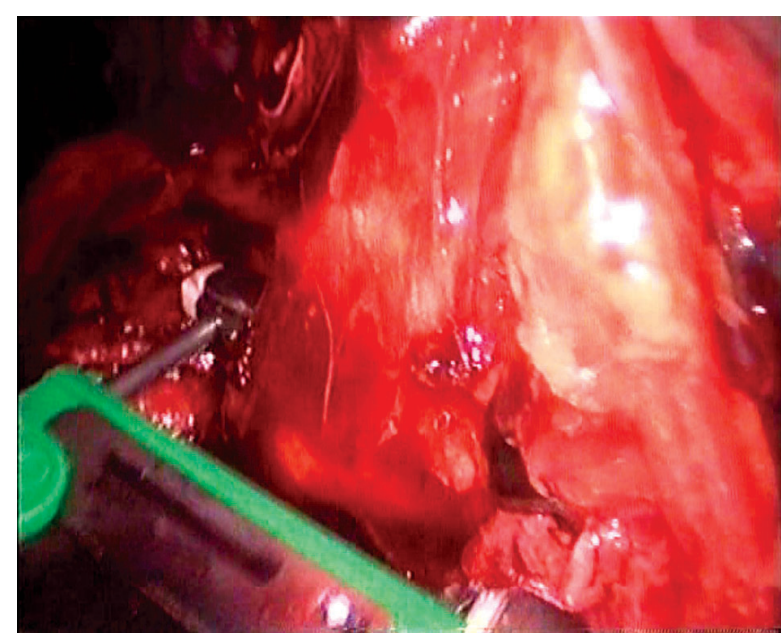

Figure 5. Lobar bronchus dissection with a TA stapler

4 patients lung cancer was resected (1 squamous cell carcinoma, 3 adenocarcinomas). One patient was treated for obstructing chondroid hamartoma located in the lobar bronchus of the right lower lobe. In 1 patient the tumour was located in the upper lobe of the left lung spreading into the lower lobe. Therefore, pneumonectomy was performed. Postoperative condition was good in all patients. There were no early complications and patients were released home on the $6^{\text {th }}$ postoperative day on average.

\section{Discussion}

Thoracoscopic lobectomy or VATS is defined as anatomical lung resection followed by mediastinal

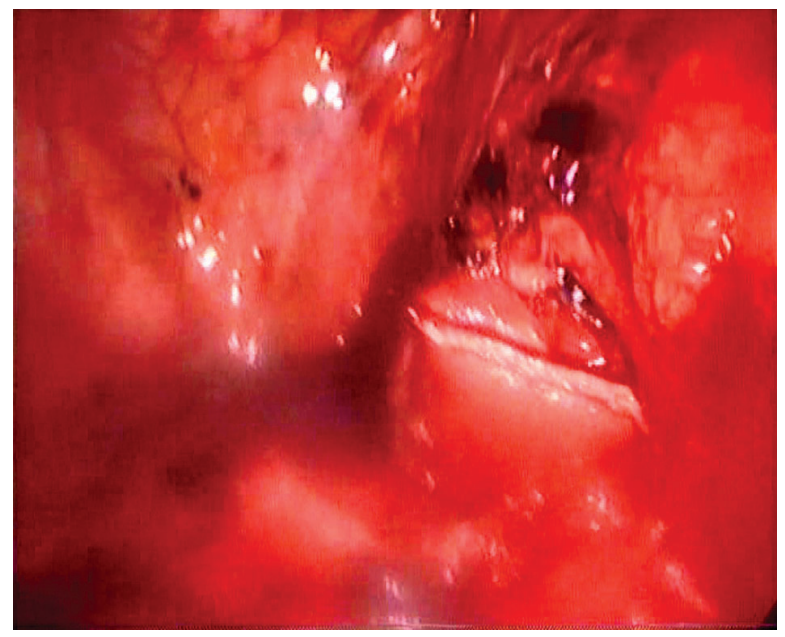

Figure 4. Suture line of pulmonary artery

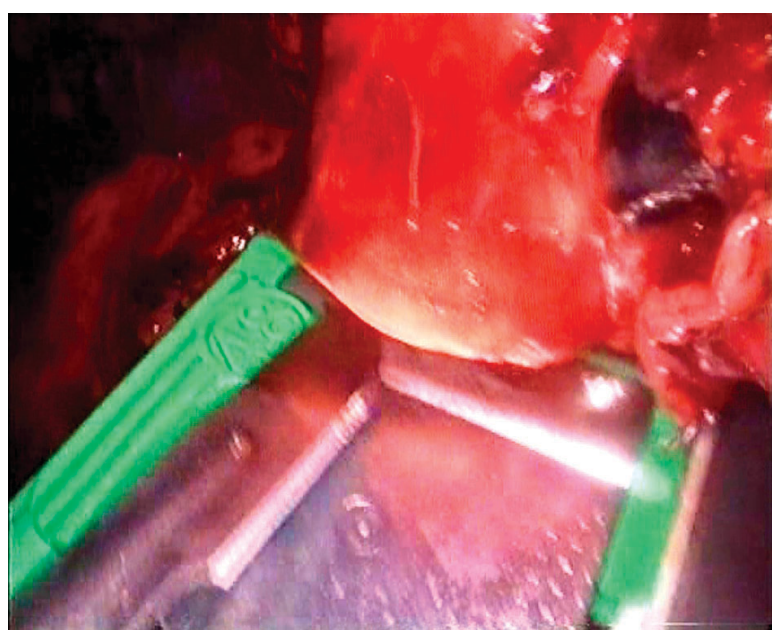

Figure 6. Dissection of lobar bronchus

lymphadenectomy using a thoracoscope and a thoracic access incision without the rib spreader being inserted into the intercostal area [3]. Contemporary studies prove that thoracoscopic lobectomy is a safe and oncologically effective strategy in the treatment of patients qualified for lobectomy [4, 5]. VATS lobectomy indications include: stage 1 of non-small cell lung cancer, lung carcinoid tumour, metastases and benign lesions which cannot be eliminated with a laser resection. The advantages of the minimally invasive approach include shorter operative time, small incision, minimal perioperative blood loss, reduction of postoperative pain, and decreased morbidity and mortality. Some authors report lower 
intensity of cytokine disturbance after VATS lobectomy compared to thoracotomy [6].

\section{Conclusions}

The advantages of VATS lobectomy have been widely discussed in the literature. The authors agree that in elderly patients with non-small cell lung carcinoma VATS lobectomy and mediastinal lymphadenectomy reduce the number of postoperative complications, and that patients recover quickly after the surgery.

\section{References}

1. Levi JF, Kleinmann P, Piquet M, Debesse B. Percutaneous parietal pleurectomy for recurrent spontaneous pneumothorax. Lancet 1990; 336: 1577-8.

2. Kuby TJ, Rice TW. Thoracoscopic lobectomy. Ann Thorac Surg 1993; 56: 784-6.

3. Solaini L, Prusciano F, Bagioni P, et al. Viceo-assisted thoracic surgery (VATS) of the lung. Surg Endosc 2008; 22: 298-310.

4. Villamizar NR, Darrabie MD, Burfeind WR, et al. Thoracoscopic lobectomy is associated with lower morbidity compared with thoracotomy. J Thorac Cardiovasc Surg 2009; 2: 419-25.

5. Seder CW, Hanna K, Lucia V, et al. The safe transition from open to thoracoscopic lobectomy: a 5-year experience. Ann Thorac Surg 2009; 88: 216-25.

6. Muraoka M, Oka T, Akamine S, et al. Video-assisted thoracic surgery lobectomy reduces the morbidity after surgery for stage I non small cell lung cancer. Jpn J Thorac Cardiovasc Surg 2006; 54: 49-55. 